\title{
Laser induced clot formation in blood treated by EDTA
}

\author{
Balsam M. Mirdan
}

Department of Physics, College of Education for Pure Science, University of Kirkuk, Kirkuk, Iraq; balsam@uokirkuk.edu.iq

Received 17 April 2013; revised 18 May 2013; accepted 26 May 2013

Copyright (c) 2013 Balsam M. Mirdan. This is an open access article distributed under the Creative Commons Attribution License, which permits unrestricted use, distribution, and reproduction in any medium, provided the original work is properly cited.

\section{ABSTRACT}

Patients under systemic (ethylenediaminetetraacetic acid) EDTA are at risk of hemorrhage for any accidental trauma even the superficial ones. This research is a trial to use $980 \mathbf{n m}$ wavelength laser light to provide coagulation for such patients in a local region without collateral thermal damage. Material and Method: $980 \mathrm{~nm}$ Diode laser operating in a continuous mode (CW) was incident on human blood treated with EDTA in Durham tubes. The used parameters were $(2.25$, $3,3.75$ and 6.75) W output power for variable exposure times $(1,3,9$ and 27$)$ s. Results: A homogenous clot was performed at 4327.84 $\mathrm{J} / \mathrm{cm}^{2}$ deposited energy density with the absence of any thermal stress in the blood. Conclusion: $980 \mathrm{~nm}$ laser wavelength provides a local photochemical bond break of the anticoagulant enhancing blood coagulation for medically compromised patients.

Keywords: $980 \mathrm{~nm}$ Laser; Blood Clot; Laser Tissue Interaction; Photochemical Interaction

\section{INTRODUCTION}

Blood coagulation is best described as a complex threshold limited intertwined set of processes that include physical, cellular, and biochemical events. It is a sequential process that involves the interaction of numerous blood components called coagulation factors. There are 13 principal coagulation factors among the better-known factors which are fibrinogen, prothrombin (factors I and II) and antihemophilic globulin (factor VIII). Clotting requires calcium to precede the cascade reaction as shown in Figure 1.

The first step in coagulation is the formation of prothrombin activator. This substance is formed in response to compounds released by the damaged vessel wall. Prothrombin activator also forms in response to changes in the blood itself; these changes result from the blood contacting the collagen fibers of the ruptured vessel. Once formed, prothrombin activator initiates the conversion of prothrombin to thrombin. Thrombin, in turn, catalyzes the conversion of fibrinogen - a soluble plasma protein-into long, sticky threads of insoluble fibrin. The fibrin threads form a mesh that traps platelets, blood cells and plasma. Within minutes, the fibrin meshwork begins to contract, squeezing out its fluid contents. This process which is called clot retraction is the final step in coagulation. It yields a resilient, insoluble clot that can withstand the friction of blood flow [1,2].

Disorders of coagulation can lead to an increased risk of bleeding (hemorrhage) or obstructive clotting (thrombosis).

Ethylenediaminetetraacetic acid (EDTA) acts as a chelator and binds with calcium which is required for

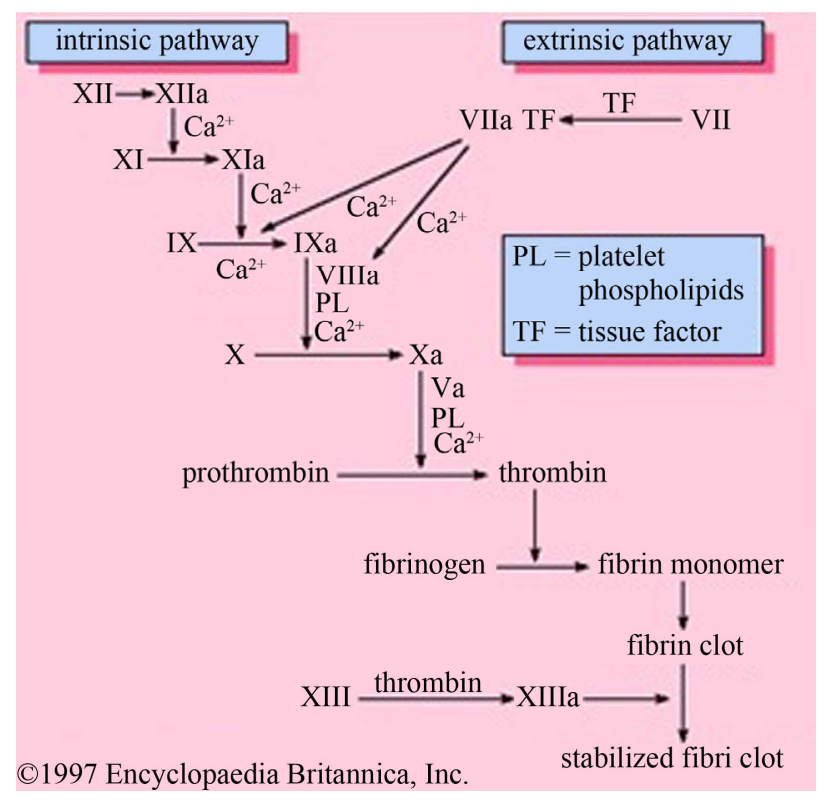

Figure 1. The blood coagulation cascade. 
coagulation thereby making calcium unavailable and inhibiting clotting [3]. As an anticoagulant, EDTA is used for treating mercury and lead poisoning [4]. It is used in a similar manner to remove excess iron from the body [5]. This therapy is used to treat the complication of repeated blood transfusions, as would be applied in the treatment of thalassemia [6]. Alternative medical practitioners believe EDTA acts as a powerful antioxidant to prevent free radicals from injuring blood vessel walls, therefore, reducing atherosclerosis [7]. The US FDA approved the use of EDTA for lead poisoning in July 16, 1953, under the brand name of Versenate, which was licensed to the pharmaceutical company Riker. It was approved as useful in trace elementsupplementation $[8,9]$. Such patients are accounted as medically compromised in dental clinics for the consequence of severe bleeding after tooth extraction and other minor operation.

This research is an attempt to provide hemostasis for patients receive EDTA treatment. This is performed by utilizing the $980 \mathrm{~nm}$ laser photochemical interaction mechanism. The mechanism depended on breaking specific bond and freeing calcium ion to provide clotting locally at the area of injury without altering the patient's general health.

\section{MATERIALS AND METHODS}

\subsection{Sample Preparation}

$10 \mathrm{ml}$ of rabbit blood was collected in anticoagulant tubes ( $0.5 \mathrm{ml}$ Potassium EDTA) KE/2.5 ml. Eventually, the blood was dispensed on Durham tubes $(5 \times 33 \mathrm{~mm})$ which were held in upright position in certain rack for the irradiation procedure.

\subsection{Laser System}

(Gigaa VELAS 60, China) emitting a $980 \mathrm{~nm}$ wavelength GaAlAs Diode laser, CW mode of operation was used. The delivery system was an optical fiber of gauges $1000 \mu \mathrm{m}$. The output power was used $(2.25,3,3.75$ and 6.75) $\mathrm{W}$ for variable exposure times $(1,3,9$ and 27$) \mathrm{s}$ TEM00 mode.

\subsection{Experiment Set Up}

The optical fiber was held at incidence angle at a constant distance from the surface of the blood inside Durham tubes (see Figure 2). The distance was kept constant to ensure the centric position of laser beam. The angle of incidence of the beam with respect to the sample surface was near $0^{\circ}$. The irradiation was carried out in the air, at atmospheric pressure of 1013 mbar, and standard relative humidity at room temperature of $27^{\circ} \mathrm{C}$.

The aiming beam of the laser system $635 \mathrm{~nm}$ wavelength was used to create a contrast for measuring the

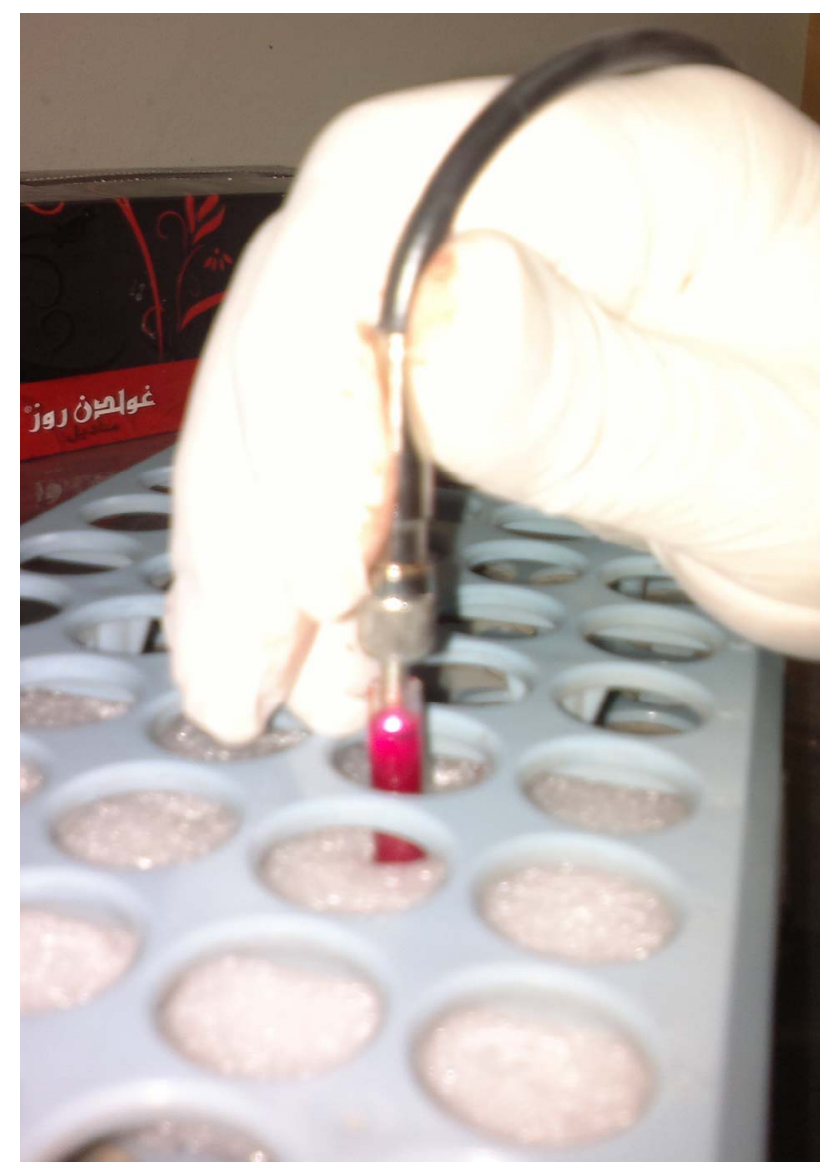

Figure 2. Irradiation of the blood in Durham tubes by $980 \mathrm{~nm}$ CW mode.

border periphery of the coagulated blood. Insulin syringe was used as a measuring tool for the coagulated blood volume.

\section{RESULTS}

The first reading of the results plotted in Figure 3 illustrates a linear relation between deposited energy density and the clotting volume.

Clinically there was a film thickness of disturbed blood spot of $1 \mathrm{~mm}$ in diameter exactly at $895.26 \mathrm{~J} / \mathrm{cm}^{2}$ deposited energy density $\left(288.46 \mathrm{~W} / \mathrm{cm}^{2}\right.$ for $3 \mathrm{~s}$ exposure time); while for nearly comparative deposited energy density of $865.38 \mathrm{~W} / \mathrm{cm}^{2}\left(865.38 \mathrm{~W} / \mathrm{cm}^{2}\right.$ for $1 \mathrm{~s}$ exposure time), nothing was obvious. Moreover, at $2596.14 \mathrm{~J} / \mathrm{cm}^{2}$ deposited energy density $\left(288.46 \mathrm{~W} / \mathrm{cm}^{2}\right.$ for 9 s exposure time), there was a layer of $0.02 \mathrm{ml}$ of coagulated blood but at $2596.14 \mathrm{~J} / \mathrm{cm}^{2}\left(865.38 \mathrm{~W} / \mathrm{cm}^{2}\right.$ for $3 \mathrm{~s}$ exposure time), there was irregular clot. The clot was formed as a sequence of boiling and air bubbles escaping out of the container during irradiation as a result to a photothermal interaction (Johansson2009). Measuring the clotting volume was difficult due to the presence of air bubbles.

A homogenous blood clot of $0.09 \mathrm{ml}$ volume with 


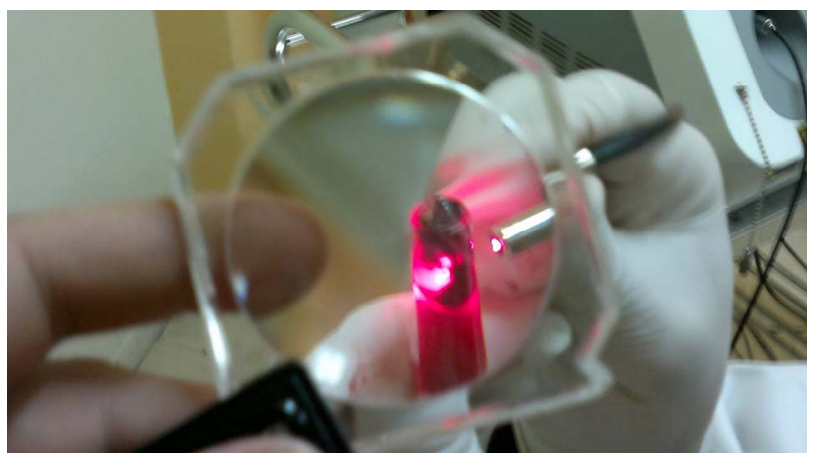

Figure 3. Clotting volume as a function of deposit laser energy density.

complete sealing of the internal border of the Durham tube was performed exactly at $4326.84 \mathrm{~J} / \mathrm{cm}^{2}$ (480.76 $\mathrm{W} / \mathrm{cm}^{2}$ for $9 \mathrm{~s}$ exposure time). Reducing the power density to $384.61 \mathrm{~W} / \mathrm{cm}^{2}$ for $9 \mathrm{~s}$ exposure time (3461.49 $\mathrm{J} / \mathrm{cm}^{2}$ ) the formed clot was smooth and the clot amount was $0.04 \mathrm{ml}$. Neither boiling nor ejection of blood droplets were noticed as shown in Figure 4.

\section{DISCUSSION}

$980 \mathrm{~nm}$ wavelength is used widely in the field of angiosurgery, angioplasty, and soft tissue welding, such procedures include coagulation and denaturation of tissue proteins with minimum thermal damage. The results of this research show the ability of $980 \mathrm{~nm}$ wavelength in clotting blood even with the presence of EDTA.

The four acid sites and the two nitrogen atoms contain unshared electron pairs, so that a single EDTA ion can form a complex with up to six sites on a given cation. Adding EDTA as an anticoagulant to the blood chelates $\mathrm{Ca}^{2+}$ forming EdetateCalicium Disodium $\left(\mathrm{Ca}^{2+}\left(\mathrm{MeCO}_{2}\right)-\right.$ $\mathrm{MeCO}_{2}$ ). The dissociation energy for this complex as reported by Lide (2007) [10] is $101.3 \mathrm{KJ} / \mathrm{mol}$. Moreover the photon energy of $980 \mathrm{~nm}$ wavelength is $20.20 \times 10-$ $20 \mathrm{~J}$ which is equivalent to $121.991 \mathrm{KJ} / \mathrm{mol}$, depending on the photochemical interaction where the absorption of the photon energy occurs within the translational electronic energy levels of the complex. Laser beam $980 \mathrm{~nm}$ photon energy is enough to break the bond

$\left(\mathrm{CH}_{3} \mathrm{COO}\right)_{2} \mathrm{Ca}$ freeing $\mathrm{Ca}^{2+}$ ion to the blood within a limited volume that can be controlled by incident laser beam to enhance the cascade reaction of clotting. Immediately, the clotting cascade is fastened by the photothermal mechanism of interaction that is induced by the $980 \mathrm{~nm}$ laser, which occurs due to the absorption of the $980 \mathrm{~nm}$ diode laser within the vibrational and rotational energy levels of the chromophores in the blood. The effect is in agreement with Mirdan, 2012 and Johansson, 2009 [11,12]. The clot formation without thermal vaporization is influenced by the exposure time rather than by the incident power density. These results agree with the

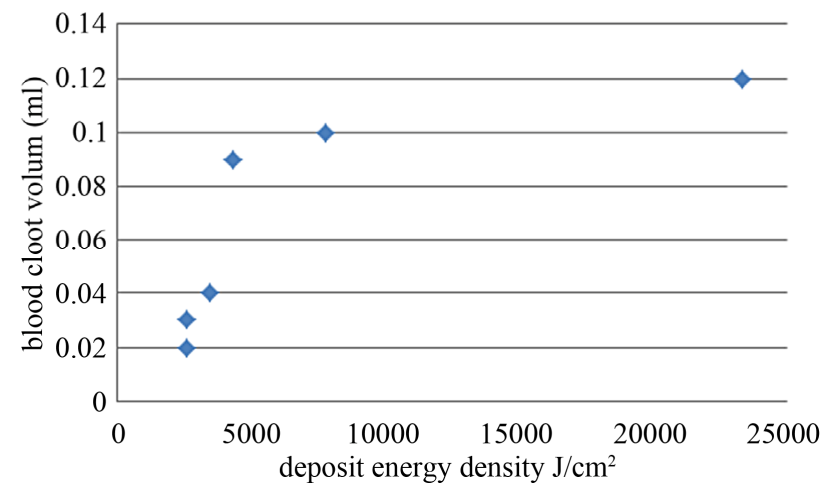

Figure 4. The clot volume as a response to laser irradiation.

map of laser tissue interaction [13].

\section{CONCLUSION}

The major conclusion is that $980 \mathrm{~nm}$ wavelength is an efficient tool to coagulate the blood in patients under the influence of EDTA without compromising their general health. Moreover, the control of the coagulation depth can be controlled by the incident beam deposit energy density. The advantage of such photochemical enhanced coagulation by using $980 \mathrm{~nm}$ wavelength can be performed with the absence of any collateral thermal damage if there is a control of laser dose parameters main exposure time and incident power density applied. Thus, 980 nm wavelength diode laser could be a useful modality of hemostasis in the surgical procedure for the patients who are on EDTA.

\section{REFERENCES}

[1] Brummel, K.E., Paradis, S.G., Butenas, S. and Mann, K.G. (2002) Thrombin functions during tissue factor-induced blood coagulation. Blood, 100, 148-152. doi:10.1182/blood.V100.1.148

[2] Haslett, C., Chilvers, E.R., Boon, N.A. and Hunter, J.A. (2002) Davidson's principles and practice of medicine. 19th Edition, Churchill, Livingstone, 200.

[3] Pal, G.K. and Pal, P. (2005) Brainstem auditory evoked potential. In: Text Book of Practical Physiology, 2nd Edition, Orient Longman, Chennai, 8.

[4] Bernhoft, R.A. (2012) Mercury toxicity and treatment: A review of the literature. Journal of Environmental and Public Health, 2012, 460508. doi:10.1155/2012/460508

[5] Spencer, N.C.O., Sunday, J.J., Erifeta, O.K., Georgina, O., Agbor, A.A., Esosa U.S. and Jenevieve, O. (2011) Comparative stabilizing effects of some anticoagulants on fasting blood glucose of diabetics and non-diabetics, determined by spectrophotometry (glucose oxidase). Asian Journal of Medical Sciences, 3, 234-236.

[6] Sharma, R.N. and Pancholi, S.S. (2011) Oral iron chelators: A new avenue for the management of thalassemia major. Journal of Current Pharmaceutical Research, 1, 
$1-7$.

[7] Uhl, H.S.M., Dysko, R.C. and Clair, R.W. St. (1992) EDTA reduces liver cholesterol content in cholesterol-fed rabbits. Atherosclerosis, 96, 181-188.

[8] Baran, E.J., Wagner, C.C. and Torre, M.H. (2002) Synthesis and characterization of EDTA complexes useful for trace elements supplementation. Journal of the Brazilian Chemical Society, 13, 576-582.

[9] Wagner, C.C. and Baran, E.J. (2010) Vibrational spectra of two $\mathrm{Fe}(\mathrm{III}) / \mathrm{EDTA}$ complexes useful for iron supplementation. Spectrochimica Acta Part, 75, 807-810. doi:10.1016/j.saa.2009.11.059

[10] David, L.R. (2006) Handbook of chemistry and physics.
Physical constants of organic components. 87th Edition, 244/483.

[11] Mirdan, B.M. (2012) Laser clot formation of the dental sockets after teeth extraction. Iraqi Journal of Laser, 11B, 56-60.

[12] Johansson, A., Conta, A.V., Weick, K., Winter, S. and Sroka, R. (2009) Temperature dynamics in blood during light application at 980 and $1470 \mathrm{~nm}$. Medical Laser Application, 24, 140-141. doi:10.1016/j.mla.2009.02.039

[13] Niemz, M.H. (2007) Laser-tissue interactions fundamentals and applications. 2nd Edition, Springer Verlag, 145200. 